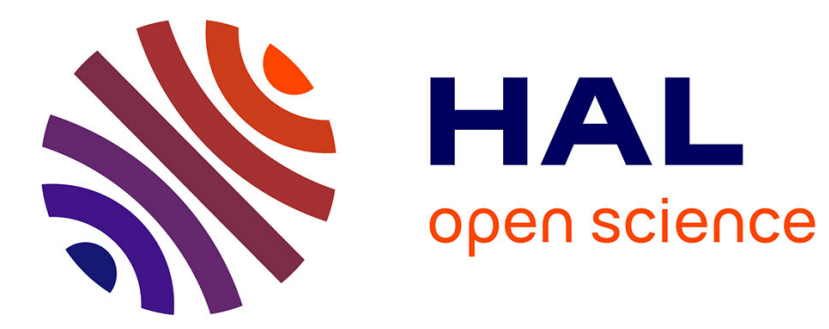

\title{
A SUPERIOR CATHODOLUMINESCENCE SPECTRAL ANALYSIS AND IMAGING SYSTEM
}

P. Wright

\section{To cite this version:}

P. Wright. A SUPERIOR CATHODOLUMINESCENCE SPECTRAL ANALYSIS AND IMAGING SYSTEM. Journal de Physique IV Proceedings, 1991, 01 (C6), pp.C6-337-C6-341. 10.1051/jp4:1991650 . jpa-00250736

\section{HAL Id: jpa-00250736 https://hal.science/jpa-00250736}

Submitted on 1 Jan 1991

HAL is a multi-disciplinary open access archive for the deposit and dissemination of scientific research documents, whether they are published or not. The documents may come from teaching and research institutions in France or abroad, or from public or private research centers.
L'archive ouverte pluridisciplinaire HAL, est destinée au dépôt et à la diffusion de documents scientifiques de niveau recherche, publiés ou non, émanant des établissements d'enseignement et de recherche français ou étrangers, des laboratoires publics ou privés. 


\title{
A SUPERIOR CATHODOLUMINESCENCE SPECTRAL ANALYSIS AND IMAGING SYSTEM
}

\author{
P.J. WRIGHT \\ Oxford Instruments Ltd, Old Station Way, GB-Eynsham OX8 1TL, Great-Britain
}

\begin{abstract}
A low loss $C L$ collection and analysis system that allows turnkey operation both for imaging and spectral analysis from 0.2 to 1.8 microns is described. Results obtained on Quantum well structures, MgO and Silicon are given. The results on Silicon show that CL spectroscopy can distinguish between regions of the sample which are averaged in the PL spectrum.
\end{abstract}

\section{Introduction}

Cathodoluminescence $(C L)$ is a useful technique in the structural and electro optical characterisation of semiconductors and reveals much information on a wealth of other materials that include ceramics and minerals. When performed in an electron microscope, both high spatial resolution images and spectra may be obtained by the use of suitable equipment.

Many designs for instruments suitable for cathodoluminescence spectral analysis and imaging in electron microscopes have been described in the literature during the past 25 years. These have often exhibited improved performance when compared with those commercially available. The prime reason for this has been the willingness of the dedicated CL researcher to mount large, heavy monochromators directly to the chamber of their microscope. The result has been a microscope committed to $\mathrm{CL}$ analysis.

However, many potential CL users have to use shared facilities and may not compromise the performance or appearance of the microscope. Subsequently, many CL systems have had the monochromator decoupled from the CL collection optics by either fibre optic bundles or quartz fibres. This has allowed the monochromator and its associated detectors to be easily decoupled from the SEM when not in use. Considerable transmission losses have been incurred and in many cases, it has been necessary to duplicate detectors to allow both spectral analysis and imaging. This has resulted in instruments which were less than optimum in both efficiency and operation.

A low loss CL collection and analysis system has recently been developed that now allows turnkey operation both for imaging and spectral analysis from $0.2 \mu \mathrm{m}$ to $1.8 \mu \mathrm{m}$. 


\section{Design Considerations}

Fundamental to the design of this system has been the production of a high resolution monochromator with an integral CL collector including a paraboloidal mirror and light guide assembly. The incorporation of lightweight composite materials for most of the structural design has resulted in the entire collector/ monochromator being light enough to mount on most SEM chambers without having to modify the vibration isolation.

A set of switching mirrors allows the CL emission to be coupled to the detectors directly for panchromatic imaging or via the monochromator, for either spectral analysis or monochromatic imaging. This has both eliminated the need to duplicate detectors and allows the highest possible transmission efficiency.

Further refinements incorporated in the design include a dual mode, two channel amplifier. The first channel allows photon counting to be performed at low signal intensities and simple v/f detection at higher signal levels. This ensures the system has the widest dynamic range possible.

The second channel accepts the signal from an InGaAs photodiode whose output is modulated by the action of a magnetically sensed chopper on the incident radiation.

The integration of a framestore into this system has resulted in two immediately obvious benefits. Firstly, images from low intensity monochromatic signals are easily obtained by averaging over a preset number of frames and secondly the pixel clock from the scan generator is easily monitored and allows the synchronisation of the scans with the modulated signals arising from both the photomultiplier tube and the cooled InGaAs photodiode.

Initial results from a wide range of materials have shown that this system is capable of producing and archiving high quality spectra and both panchromatic and monochromatic images. These have included quantum well structures, semiconductor materials and devices, epitaxial diamond films, bulk diamonds high temperature superconductors and ceramic materials.

Many of those materials have been studied at room temperature, $77 \mathrm{~K}$ and 4.2K using compatible cooling stages. This has characteristically increased the signal to noise ratio by orders of magnitude, as well as reducing sample damage by allowing lower operating conditions to be used.

\section{Results}

Alternating layers of semiconductors and wider band gap materials are important in the manufacture of many electro optical devices. When these layers are smaller than $50 \mathrm{~nm}$, they are known as Quantum Well structures. Although cross section micrographs of these structures can reveal the thicknesses of these structures, sample preparation is normally difficult. $\quad C L$ can reveal this information in spectroscopic form by relying on the electron beam to stimulate electron transitions from all wells within its interaction volume. An example of the type of spectra obtained is shown in Fig. 3 . 


\section{$\underline{\text { Silicon }}$}

The exceptional sensitivity of this system enables both CL spectra and images to be obtained from silicon. Figures 7 to 10 (courtesy of Dr $V$ Higgs, King's College, University of London) show results obtained on a silicon sample that had been plastically deformed then deliberately contaminated with copper.

The CL spectra distinguish between the regions on and off the slip lines, which show up as bright lines in the CL image and in the EBIC image. The PL spectra gives an average spectrum, owing to the poorer spatial resolution of this technique.

\section{Conclusions}

The monoCL system from Oxford Instruments allows CL images and spectra to be obtained from a wide variety of important materials. The careful design of the optical system reduces previously experienced losses and facilitates operation at lower conditions than before. This has obvious benefits in maximising resolution and minimising beam damage. Increased signal levels and reduced beam damage are experienced in many materials when cooled to liquid nitrogen or helium temperatures.

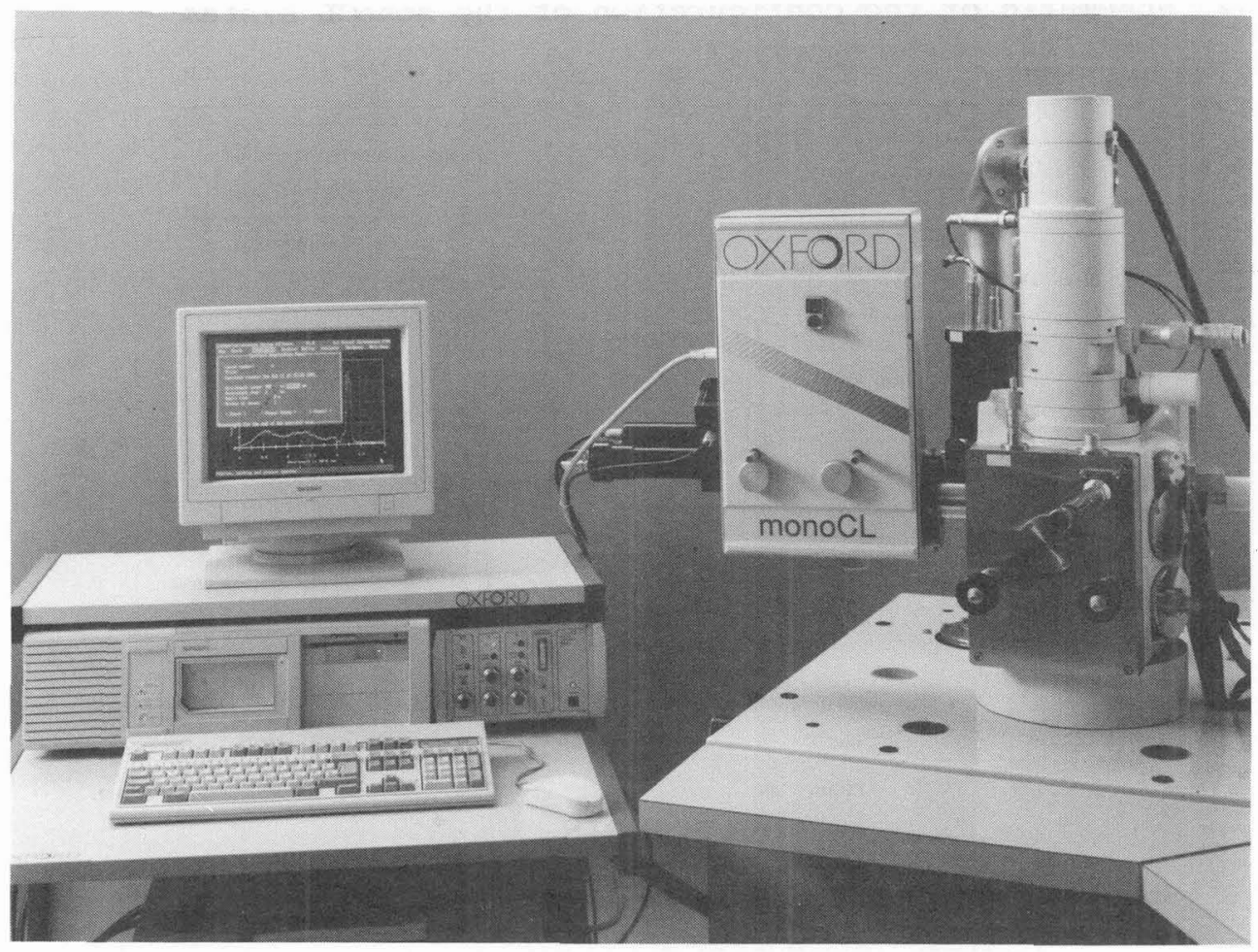

Fig. 1 The monocl attached to a JEOL JSM 840 SEM 


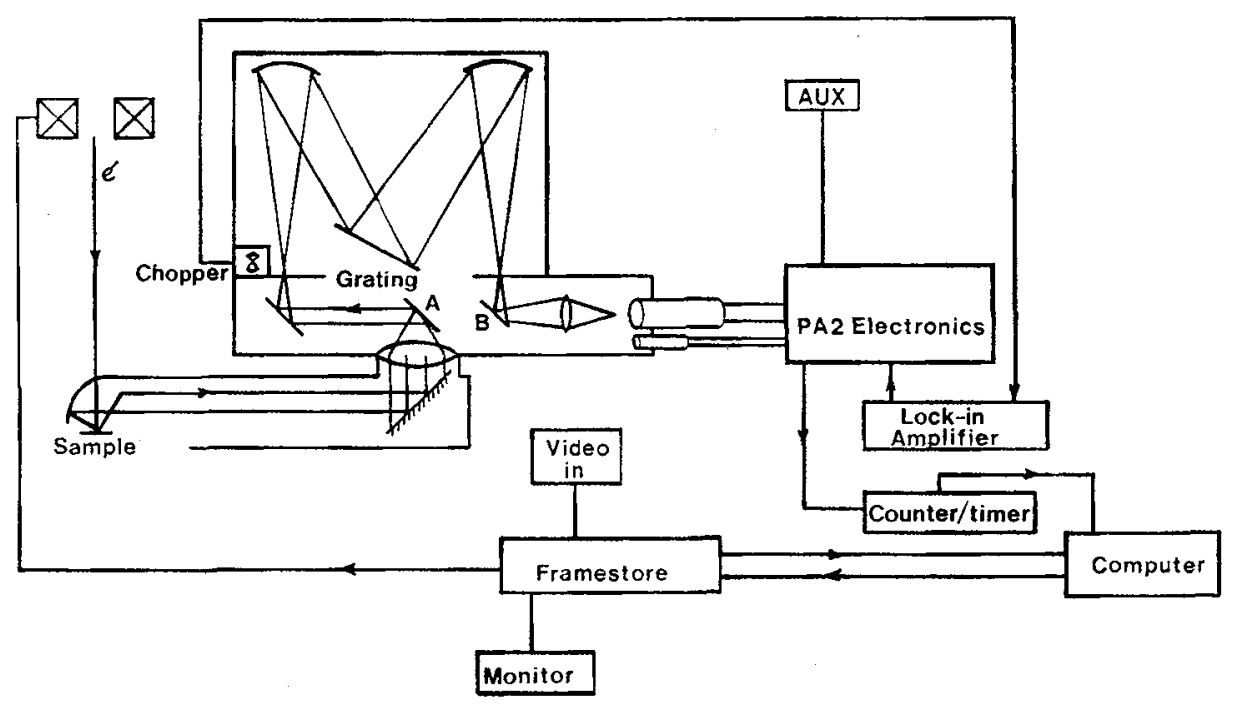

Fig. 2 Schematic of the configuration of the monocL system

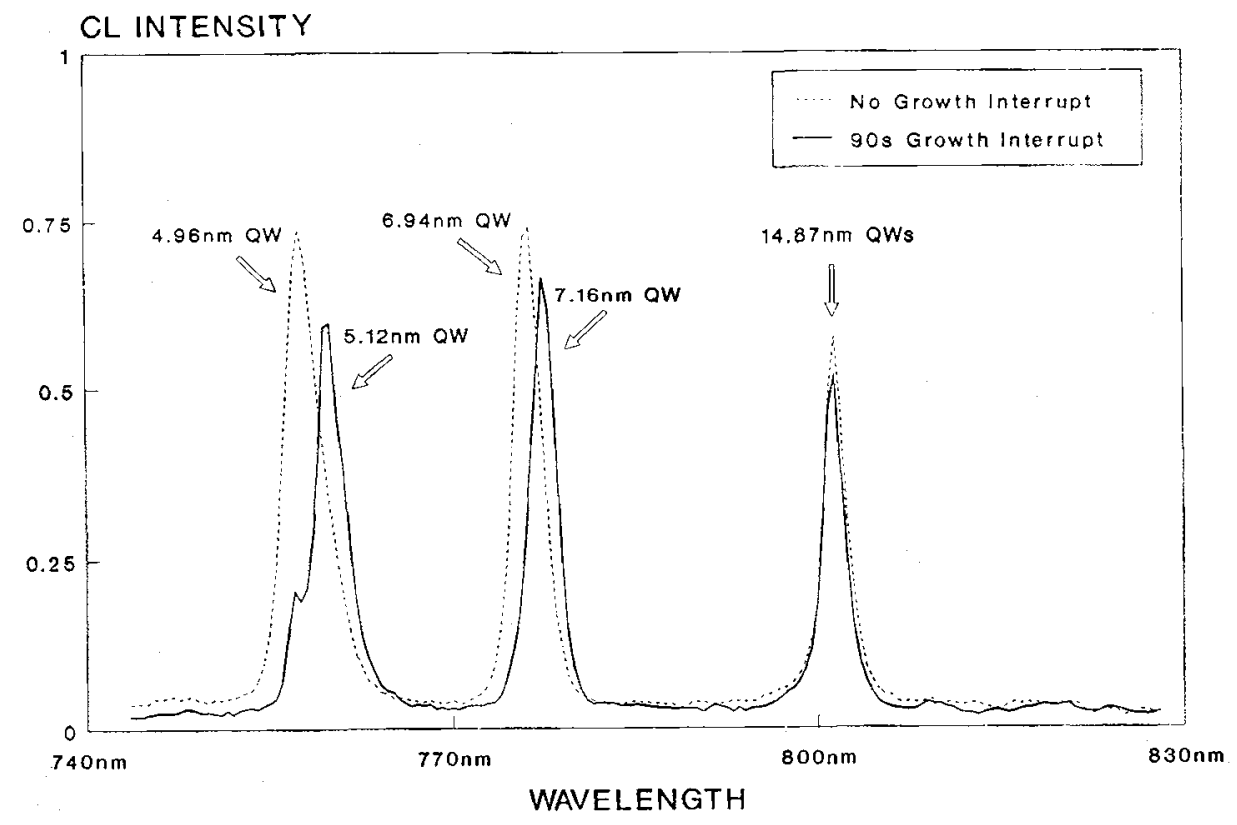

Fig. 3 Spectra from Quantum Well structures 


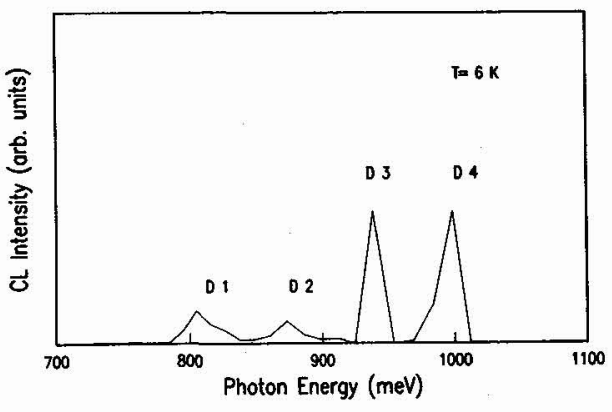

Fig. 4 CL spectrum of Si, region on slip line

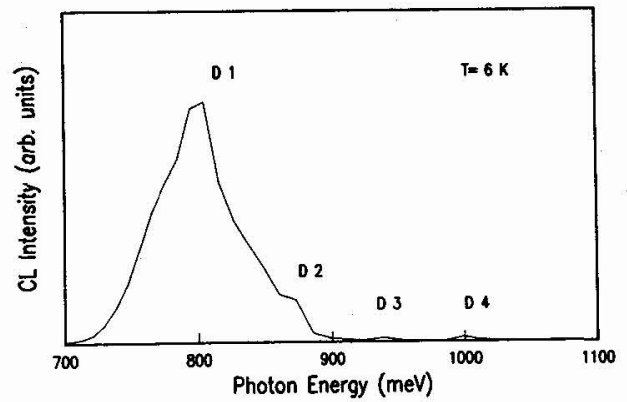

Fig. 5 CL spectrum of $\mathrm{Si}$, region off slip line

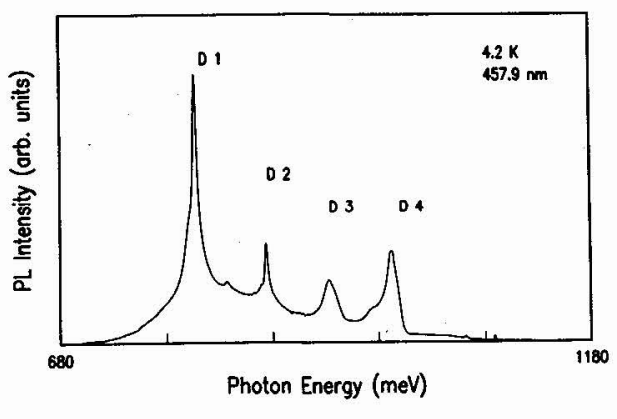

Fig. 6 PL spectrum of $\mathrm{Si}$

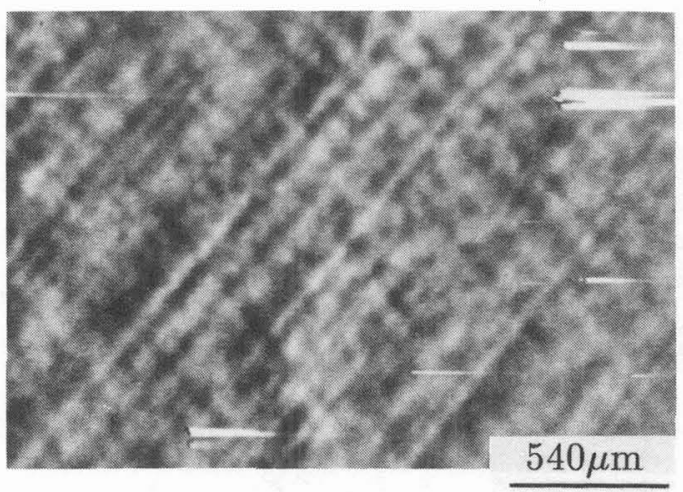

Fig. 7 CL image of Si, showing slip lines 